\title{
Qualimetric Analysis of Pipelines with Corrosion Surfaces in the Monitoring System of Oil and Gas Enterprises
}

\author{
Volodymyr Yuzevych, Nataliia Pavlenchyk, Olha Zaiats, Nelli Heorhiadi, Viktoriia Lakiza
}

\begin{abstract}
The introduction of new technologies for diagnosing underground metal pipelines with dangerous surface defects is a practically important task. That is why studies aimed at improving the methods of assessing the quality of deformed metal pipelines and structural elements are necessary and relevant.

The evaluation of the effectiveness of engineering and technological solutions for oil and gas enterprises needs improvement. In this context, an important task is to solve the problem of quality control (including durability) of gas and oil transportation systems and the improvement of appropriate metrological support.

Based on surface physics and fracture mechanics, development of a methodological approach to assessing the quality and resource of underground metal pipelines (UMP) of oil and gas enterprises, taking into account the constructions strength, corrosion fatigue, parameters of corrosion protection and metrological support.

Results of processing of normative documents and scientific works in the field of gas transportation enterprises, as well as methods of surface physics, mechanics of deformed solid body, fracture mechanics, qualimetry regarding the system "pipeline (UMP) - coating”.
\end{abstract}

A new criterion for the strength of the surface of a metal underground pipe is proposed, which characterizes the peculiarities of bond fractures (adhesion) between the coating and the metal.

Using the criterion of the strength of a metal tube with a defect in the electrolyte, the dependence of the critical internal pressure of the gas pipeline (UMP) on the geometric and energy (elastic and plastic) parameters of the metal, as well as the current of the anodic dissolution, which characterizes the features of the crack propagation at the bottom of the corrosion cavern.

On the basis of surface physics and fracture mechanics obtained, a methodology for evaluating the quality of underground metal pipelines of oil and gas enterprises was developed to determine their resource, taking into account strength, corrosion fatigue, parameters of corrosion protection and metrological support.

Revised Manuscript Received on April 15, 2020.

* Correspondence Author

Volodymyr Yuzevych, Department of Electrophysical Methods of Non-Destructive Testing, Karpenko Physico-mechanical Institute of the NAS of Ukraine, Lviv, Ukraine

Nataliia Pavlenchyk*, Department of Economics and Management, Lviv State University of Physical Culture, Lviv, Ukraine;

E-mail: pavlinova75@gmail.com

Olha Zaiats, Department of Civil Law Disciplines, Lviv State University of Internal Affairs, Lviv, Ukraine

Nelli Heorhiadi, Department of Management and International Business, Lviv Polytechnic National University, Lviv, Ukraine

Viktoriia Lakiza, Department of Management and International Business, Lviv Polytechnic National University, Lviv, Ukraine
Keywords: pipeline, metal, oil and gas enterprises, structure degradation, fracture, cavern, crack, metrology, quality control, non-destructive testing, neural network.

\section{INTRODUCTION}

The assessment of the reliability of underground metal pipelines (UMP) of oil and gas enterprises is of particular interest during their operation in conditions of mechanical loading and aggressive influence of soil electrolyte. Important for UMP is the state of surface metal layers protected by dielectric coatings. On the surface of the metal possible defects (cavities, cracks).

In the process of complex analysis of stress-strain state (SSS) UMP, it is expedient to take into account changes in internal pressure and parameters that characterize the interaction of metal with soil electrolyte in coating defects.

In conditions of economic development it is necessary to provide reliable transport flows of gas, oil, chemical industry products. The introduction of new technologies for diagnosing UMP with dangerous defects is a practical task. That is why research aimed at improving the technology for assessing the quality of deformed metal pipelines and metal structures is necessary and relevant.

\section{LITERATURE REVIEW AND PROBLEM STATEMENT}

The quality problem (in particular, strength) of the UMP is related to the effectiveness of the methods for assessing the SSS of the metal pipe, as well as the metrological characteristics of the information-measuring systems (IMS), in particular, the corresponding devices (polarization potential meters (VPP, VPP-M with the determinant of geographical coordinates GPS with memory and interface Fig. 1, Contactless Current Meter (BVS)) to determine the characteristics of a corrosive environment [1-4].

Protective coatings and cathodic protection installations (ICP) are used to protect the UMP from the destructive influence of the soil electrolyte [1-5].

Simulation of corrosion processes in the gas pipeline, taking into account mechanical and electrochemical parameters of the state and energy characteristics of phase-layer layers, can be carried out on the basis of the mathematical relations of the article [6].

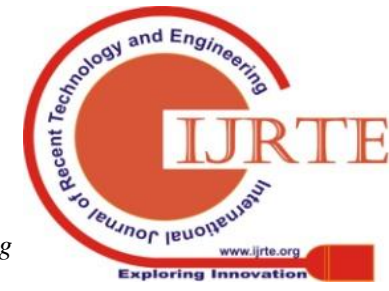


The principles of diagnosing complex systems for oil and gas companies, taking into account measures to optimize the diagnostic value of research methods and risks, are presented in [7]. (a)

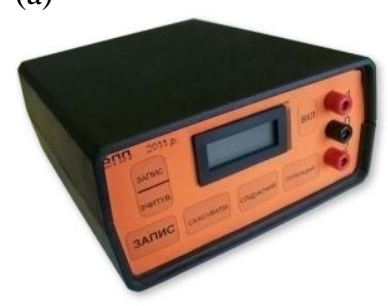

(b)

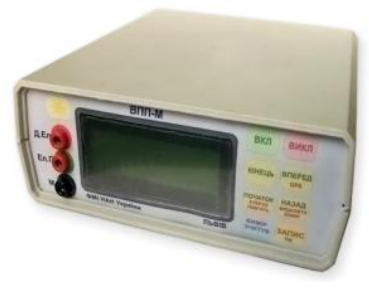

Fig. 1. Digital instruments for measuring constant and alternating electric voltages and determining the polarization potential: (a) - VPP, (b) - VPP-M* Device for determining the location and measurement of potential of underground pipelines / R. Dzhala, B. Verbenets; applicant and patent holder Karpenko Physico-mechanical Institute of the NAS of Ukraine, Ukraine. - No. u2010 00756; stated. 26.01.2010; Positive decision 08.06.2010; published Aug 25, 2010, Bul. No. 16.

However, the works [1-7] do not take into account the criteria of strength and plasticity and the influence of vibrations, which leads to a violation of the fatigue strength of the metal pipeline, no results of metrological research of diagnostic devices are presented. In work [8] an approximate methodology for evaluating the resource of an underground steel pipe is presented if the corrosion cavity extends from the side of the soil (external corrosive environment). As a result of the works $[9,10]$ using artificial neural networks (ANN), it is advisable to analyze the currents and voltages obtained as a result of the survey of the pipeline with non-destructive control devices and to predict the resource of the gas pipeline with a corrosion defect, taking into account the effect of corrosion fatigue of the metal and the metrological aspects of the measured information. The article [11] presents effective modern methods for defect estimation in pipelines. But in these articles [8-11] the influence of the external dielectric coating and the features of the nonlinear nature of the propagation of the corrosion defect in the direction of the center of the underground metal pipe were not taken into account.

From the above analysis of articles [1-11], it follows that the justification of the resource (evaluation of the terms of use) of UPM is due to the features of fatigue longevity [5] and with the connection of the critical viscosity of the fracture of the metal pipe with parameters that characterize the dimensional effect strength [12]. The multi-vector method of evaluating investment decisions on the problem [13, 14] deserves attention, but it needs to be improved to evaluate the effectiveness of engineering and technological solutions. In this context, given the information [1-33], it is necessary to solve an important problem of oil and gas enterprises, which is related to the quality control (in particular, strength) of the operation of gas and oil transportation systems and the improvement of the corresponding metrological support.
*Note: Pat. 52293 Ukraine, IPC (2009) G 01 V 3/00, C 23 F 13/00.

\section{THE AIM AND OBJECTIVES OF THE STUDY}

The aim of the work is to develop a methodological approach to the assessment of the quality of UMP on the basis of surface physics and fracture mechanics to determine the resource of underground metal pipelines (UMP) of oil and gas enterprises, taking into account strength, corrosion fatigue, parameters of anticorrosion protection and metrological support.

\section{FORMING THE TOOLSET FOR APPRAISE OF THE STRENGTH OF THE UNDERGROUND METAL PIPELINE WITH A DEFECT: METHODOLOGICAL BACKGROUND}

Consider the metal pipeline system (MP) - dielectric cover (DC). In the first stage we describe the possibility of fracture DC.

We consider an anticorrosive polymeric three-layer coating on the basis of extruded polyethylene, which corresponds to DSTU 4219-2003. The strength criterion for such a DC is formulated as [15]:

$$
\sigma_{0}-C_{0}+C_{1} P(J) \tau_{0}+C_{2}\left(\tau_{0}\right)^{2}=0
$$

where $P(J)$ - function describing the shape of limit surface in deviatoric plane; $\sigma_{0}=I_{1} / 3$ - mean stress; $\tau_{0}=\left(2 J_{2} / 3\right)^{0,5}-$ octahedral shear stress; $I_{1}-$ first invariant of the stress tensor; $J_{2}, J_{3}-$ second and third invariant of the stress deviator, $J=3 \sqrt{3} J_{3} /\left(2\left(J_{2}\right)^{1,5}\right)$ - alternative invariant of the stress deviator; $\alpha, \beta, C_{0}, C_{1}, C_{2}-$ material constants, which are set experimentally [15].

Between the coating and the metal there should be sufficient adhesion. The energy of adhesion bonds $\gamma_{a d}$ and its change $\Delta \gamma_{a d}$ depend on the energy characteristics of the coating and metal $[16,17]$. We formulate new aspects of the strength criterion between metal and coating, taking into account the results of the paper [16]:

$$
\begin{gathered}
\Delta \gamma_{m} \leq \Delta \gamma_{m^{*}}, \Delta A_{a d} \leq \Delta A_{a d *}, \\
\Delta \sigma_{m} \leq \Delta \sigma_{m^{*}}, \Delta \gamma_{\text {vad }} \leq \Delta \gamma_{a d *}
\end{gathered}
$$

where $\Delta \sigma_{m}$ is a change in the interphase tension; $\Delta \gamma_{m}$ is a change in interphase energy; $\Delta$ is the symbol of the deviation (change) of the parameter or energy characteristic of the surface (interphase) layer; $\Delta A_{a d}-$ change of adhesion; $\Delta \sigma_{m *}$, $\Delta \gamma_{m *}, \Delta A_{a d *}, \Delta \gamma_{a d *}-$ are empirical constants.

The correlation (1), (2) constitute in the complex a new version of the strength criterion for the metal pipeline system (UMP) - cover (DC). The parameters of the expression (1) are determined on the basis of the experiment, and the parameters of the correlation (2) are evaluated on the basis of the computational experiment.

In recent years, the use of composite coatings on the basis of graphene for metal elements of structures is promising [18]. Such materials should cover pipes and other responsible metal structures, since graphene is stronger than other coating materials. 
The method for evaluating the energy characteristics of the interphase layers of the Graphene-metal system in this case is presented in [16].

If the adhesion is broken, then there is a detachment of the coating and in those places from the side of the soil can penetrate the aqueous solution of soil electrolyte. The solution of the electrolyte causes the formation of a cavity on the outer surface of the metal. The cavity extends toward the center of the pipe.

The criteria of the boundary plasticity $\Theta_{c}$ and strength $\Theta_{u}$ for the peak of the defect (cracks) can be formulated in the form of dimensionless correlations [19]:

$$
\begin{gathered}
\Theta_{T}=\frac{\varepsilon_{i}}{\varepsilon_{i c}}+\frac{\varepsilon_{0}}{\varepsilon_{0 c}}, \\
\Theta_{S}=\frac{\varepsilon_{i} \cdot \cos \varphi_{r}}{\varepsilon_{i u}}+\frac{\varepsilon_{0}}{\varepsilon_{0 u}},
\end{gathered}
$$

where $\varepsilon_{i}$ - is the intensity of deformation; $\varepsilon_{0}$ - is a volumetric deformation; $\varphi_{r}-$ is the angle of deviation deformation, rad; $\varepsilon_{i c}-$ is the intensity of destructive deformations; $\varepsilon_{0 c}$ - destructive volumetric deformation; $\varepsilon_{i u}$ - is the limiting intensity of deformations; $\varepsilon_{0 u}-$ is the limiting volumetric deformation.

We proceed from the deformation components $\varepsilon_{j k}(3)$, (4) to mechanical stresses $\sigma_{j k}$ on the basis of the correlation of the model described in the papers $[16,20](j, k=1,2,3)$. In particular, the Hooke's law equation is used.

Due to the influence of the internal pressure of the gas in the pipe in the vicinity of the top of the crack, a zone of plastic deformation appears corresponding to the pressure $p_{c r l}\left(\sigma_{T}\right)$, and in the second stage, the critical state $p_{c r 2}\left(\sigma_{S}\right)\left(\sigma_{T}-\right.$ is the boundary of plasticity; $\sigma_{S}$ - Is the tensile strength (breaking stress)) [8]. The expression for $p_{c r 2}\left(\sigma_{S}\right)$ is written similarly to $p_{c r l}$ with respect to the boundary of strength $\sigma_{S}[8]$ :

$$
\begin{gathered}
p_{c r 1}=w_{S} \cdot \sigma_{T} ; p_{c r 2}=w_{S} \cdot \sigma_{S} ; \\
w_{S}=\frac{2 \sqrt{2} \cdot d}{3 K_{t} \cdot D} \cdot \frac{\left(1,5+K_{z}\right) \cdot\left(r_{0}+c\right)^{4}}{\left(r_{0}+c\right)^{4}+0,5 \cdot r_{0}^{2}\left(r_{0}+c\right)^{2}+r_{0}^{4}}
\end{gathered}
$$

where $h, c-$ the depth of the cavity and the crack, respectively; $D, d$ - the outer diameter of the pipe and the thickness of the pipe wall; $r_{0}$ - radius of curvature of the juvenile surface projection; $h+c+r_{0}$ - total depth of defect; $K_{z}\left(h, c, d, r_{0}\right)-$ is an expression that is functionally dependent on the geometric parameters of the defects (obtained analytically).

Parameters $p_{c r 1}$ and $p_{c r 2}$ are important for assessing the strength, reliability, and resource of the pipeline under the influence of external corrosive environment.

The information necessary to evaluate the conditions for degradation of the structure and the fracture of underground metal pipes and, consequently, the quality of the pipeline, is established on the basis of the analysis of mechanical loads environmental characteristics and electrical currents and potentials obtained by equipment of the BVC and VPP [1-4] (see Fig. 1).

\section{RESEARCH RESULTS AND DISCUSSION}

\subsection{Improving the criteria of quality for metal with surface (interphase) defects}

In the same way as in articles [2, 3], the multiplicative qualimetric quality criterion for an underground pipeline metal taking into account the system of cathodic protection (CPS) is presented as:

$$
Z_{1}=\prod_{i=1}^{m} k_{i}=k_{1} \cdot k_{2} \cdot k_{3} \cdot k_{4} \cdot k_{5} \cdot k_{6} \cdot k_{7} \cdot k_{8} \cdot k_{9} \Rightarrow \max
$$

where $k_{j}$ are parameters $(i=1,2, \ldots, 9)$ that characterize the plan for improving the technological process [1, 17], in particular: $k_{l}$ - data management and control and monitoring of data relating to the monitoring of the "metal-coating" system; $k_{2}$ - susceptibility and risk methods; $k_{3}$ - methods for evaluating the state of interphase layers, taking into account (1), (2); $k_{4}$ - methods for evaluating the state of surface defects (cavities, cracks), taking into account the criteria of plasticity and strength, (3) - (5); $k_{5}$ - methods of evaluating the results of repairs; $k_{6}$ - methods of providing pipeline safe working pressure, taking into account (5); $k_{7}$ - methods of selecting preventive and mitigating measures; $k_{8}$ - emergency response techniques; $k_{9}$ - performance management methods (key performance indicators)

Let's also mention the quality criterion $Z_{2}$ in the additive form similar to $[2,3]$ and the combined criterion $Z_{K}$, taking into account the set of parameters $k_{j}[2,3,21]$ :

$$
\begin{gathered}
Z_{2}=a_{1} k_{10}+a_{2} k_{11}+a_{3} k_{12}+a_{4} k_{13}+ \\
+a_{5} k_{14}+a_{6} k_{15}+a_{7} k_{16}+a_{8} k_{17}+a_{9} k_{18} \\
Z_{K}=a_{10} Z_{1}+a_{11} Z_{2},
\end{gathered}
$$

where $a_{j}(j=1,2, \ldots, 11)-$ coefficients of validity, which determine the expert method. Parameters $k_{j}$ characterize [2, 3, 21, 29]:

$k_{10}$ - methods of providing intermediate and periodic reviews;

$k_{11}$ - management of change and well-defined triggers to re-evaluate;

$k_{12}$ - methods for organizing roles and responsibilities;

$k_{13}$ - training and knowledge sharing;

$k_{14}$ - methods of forming links with staff and their engagement;

$k_{15}$ - methods for determining the strengthening of material (metal) $n_{Z}$;

$k_{16}-$ methods for determining the boundary of corrosion fatigue $\sigma_{v e}\left(N_{C}\right)\left(N_{C}\right.$ - total number of cycles);

$k_{17}$ - methods that characterize the influence of the coating on the stability of the structure (metal coating) $K_{S}$;

$k_{18}$ - methods for evaluating the term of trouble-free operation of the $T_{S}$ (resource) of construction (coating pipes) taking into account $N_{C}$.

In the first expression it is choose:

$$
a_{1}=a_{2}=\ldots=a_{9}=1 / 9 ; \quad a_{10}=a_{11}=0,5 .
$$


Coefficient $k_{13}$ takes into account the use of deep learning neural network. It corresponds to a probabilistic generative model, which has functions in several layers of hidden nodes [22]. The neural network is used to process the results of the site survey (PMT) with the help of apparatus (BVC) in conjunction with (VPP) [2]. With the help of the neural network, a model is developed that gives a prediction of the depth and length of the corrosion defect that can be used to calculate the corrosion rate [10].

The disadvantage of the testing set is that it is not bulky. In addition, during training, the neural network, taking into account this initial testing set, functions as a "hidden calculation layer", which imposes certain limitations on the corresponding results for the forecast of the resource of the pipe.

The correlation (1)-(8), supplemented by the methods of the articles [5, 6, 10, 22], form the basis of a new mathematical model whose results help to predict the reliability of the pipeline in terms of the probability of failure and the evaluation of the strength of the elements of steel structures and of the resource.

\subsection{Appraise of parameters UMP with corrosion defect in the monitoring system of oil and gas enterprises}

Taking into account the correlation of the surface physics and the mechanics of a deformable solid, a mathematical model [6] was constructed to evaluate the parameters characterizing the mechanical state of the metal in the vicinity of the cavity, on which the crack is continued (Fig. 2). Using the experimental values of the yield point $\sigma_{T}$, the depths of the cavity $h$ and the crack $c$, a critical value of the internal pressure $p_{c r}$, was found which corresponds to the plastic state of the metal at the top of the crack [8, 23, 29].

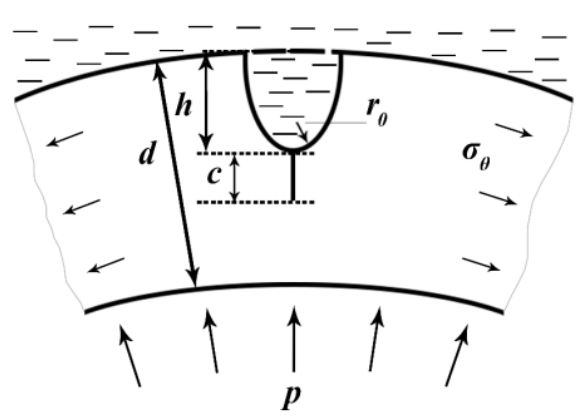

Fig. 2. A pipe with a corrosion cavity and a crack in the electrolyte [29]

The average value of the rate of corrosion of the metal (steel) on the surface of the UMP in coating defects may be approximately in the range of $0,02 \div 0,15 \mathrm{~mm} /$ year [1].

Consider the concrete situation for an underground steel pipe, the steel grade of which is X42 [11]. Consider the initial dimensions of the pipe, the cavity, the limits of the plasticity and strength of the metal, the effect of corrosion fatigue, the initial rate of corrosion in the coating defect, and other parameters that are useful for solving the problems of diagnosing the corrosion process. In particular, let [11]: $p=5,7 \mathrm{MPa}$ - pressure inside the pipe; $d=22,1 \mathrm{~mm}$ - thickness of the pipe wall; $D=2 R=0,914 \mathrm{~m}$-diameter of the pipe; $\sigma_{T}=$ $290 \mathrm{MPa} ; \sigma_{S}=415 \mathrm{MPa}$.
The fracture of the pipe will be (for example) when the effective dimension of the defect $(h+c)$ reaches a depth of $h+c=17.1 \mathrm{~mm}$ [11]. In this case, the mechanical stresses at the top of the crack are close to the critical value, which according to the criterion of maximum tensile stresses corresponds to the condition of fracture, that is, the strength limits $\sigma_{S}=415 \mathrm{MPa}$. An integral quality criterion for $Z_{K}(7)$ was used to assess the monitoring of a specific pipe line (pipe), and the factor of strength was adopted $K_{M}=1.47$. The method of estimating the coefficient $K_{M}$ is given in [24].

The effect of corrosion fatigue will be taken into account on the basis of the consideration of the known experimental data for steel of the X42 mark [11], similarly to the article [5], and the initial value of the corrosion current density in the coating defect is taken $j_{C O}=0,13 \mathrm{~A} / \mathrm{m}^{2}$.

The critical depth of the defect meets the condition of $0,78 d$ [11], and the time to reach the crack of this depth depends on the initial rate of corrosion of $0,13 \mathrm{~A} / \mathrm{m}^{2}$ and the characteristics of vibrational observations associated with the operation of compressor stations (CS) [25]. The rate of corrosion in the coating defect over time decreases and is established on the basis of the analysis of the problem of the propagation of the corrosion defect taking into account the correlation (1)-(7). If the initial rate of the anode current is $j_{C 0}=0,13 \mathrm{~A} / \mathrm{m}^{2}$, then the metal life of the pipe (i.e., the time of reaching a dangerous depth of $h+c=17,1 \mathrm{~mm}(d=22,1 \mathrm{~mm})$ in this particular example would be approximated $\tau=114$ years, if we did not take into account $K_{M}$ and the nonlinear nature of the change in the rate of corrosion of $j_{C}$ in the coating defect. Since the corrosion process is nonlinear, based on the model (1)-(8), taking into account corrosion fatigue and strength and quality criteria, the developed method and means of the computational experiment have established that the propagation time of the crack, that is, the metal pipe's resource, is $\tau_{L}=129$ years $\left(\delta=\tau_{L} / \tau=1,13\right)$, and taking into account $K_{M}-\tau_{L^{*}}=88$ years. Metrological analysis allowed to estimate the uncertainty of the values of $j_{C}$ and $\tau_{L}, \tau_{L^{*}}$ and find that they do not exceed $9 \%$.

The main results of the conducted researches were approved at the enterprise - Affiliate Management of main gas pipelines "LVIVTRANSGAS" (Public Joint Stock Company "UKRTRANSGAS”).

\section{CONCLUSION}

According to the results of the study such conclusions and recommendations of the theoretical and practical nature have been formulated [1-33]:

1. A new criterion for the strength of the surface of a metal underground pipe is proposed, which characterizes the conditions for the bond fractures (adhesion) of the coating with metal.

2. Using the strength criterion of a metal pipe with a defect in an electrolyte, the dependences of the critical internal pressure of the gas pipeline on the geometric and energy (elastic and plastic) parameters of the metal are described, which characterize the current of the anode dissolution and the propagation of the crack at the bottom of the corrosion cavity.

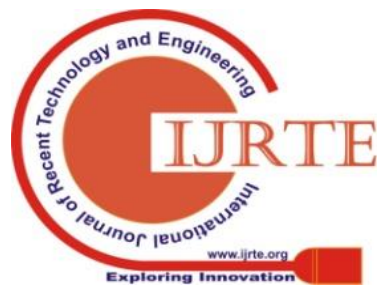


3. On the basis of surface physics and destructive mechanics, a methodology for assessing the quality of underground metal pipelines of oil and gas enterprises has been developed to determine their resource, taking into account strength, corrosion fatigue, parameters of anticorrosion protection and metrological maintenance.

4. On the basis of the obtained results, we evaluate the strength, reliability and residual life of the underground pipeline in the monitoring system of oil and gas enterprises.

\section{REFERENCES}

1. Technical diagnostics of materials and structures: Reference manual Ed.-in-chief Z. T. Nazarchuk. Vol. 4: Electrophysical methods for nondestructive testing of defects in structural elements / R. M. Dzhala (ed), V. R. Dzhala, I. B. Ivasiv, V. G. Rybachuk, V. M. Uchanin. Lviv: Prostir-M, 2018. 356 p. (In Ukr.).

2. Lozovan, V., Dzhala, R., Skrynkovskyy, R., \& Yuzevych, V. (2019). Detection of specific features in the functioning of a system for the anti-corrosion protection of underground pipelines at oil and gas enterprises using neural networks. Eastern-European Journal of Enterprise Technologies, 1(5(97)), 20-27. doi http://dx.doi.org/10.15587/1729-4061.2019.154999.

3. Lozovan, V., Skrynkovskyy, R., Yuzevych, V., Yasinskyi, M., \& Pawlowski, G. (2019). Forming the toolset for development of a system to control quality of operation of underground pipelines by oil and gas enterprises with the use of neural networks. Eastern-European Journal of Enterprise Technologies, 2(5(98)), 41-48. doi http://dx.doi.org/10.15587/1729-4061.2019.161484.

4. Yuzevych, V., Skrynkovskyy, R., \& Koman, B. (2018). Intelligent Analysis of Data Systems for Defects in Underground Gas Pipeline. 2018 IEEE Second International Conference on Data Stream Mining \& Processing (DSMP). doi: https://doi.org/10.1109/dsmp.2018.8478560.

5. Yuzevych, L., Skrynkovskyy, R., \& Koman, B. (2017). Development of information support of quality management of underground pipelines. EUREKA: Physics and Engineering, 4, 49-60. doi: https://doi.org/10.21303/2461-4262.2017.00392.

6. Yuzevych, V. M., Dzhala, R. M., \& Koman, B. P. (2018). Analysis of Metal Corrosion under Conditions of Mechanical Impacts and Aggressive Environments. Metallofizika i Noveishie Tekhnologii, 39(12), 1655-1667. doi: https://doi.org/10.15407/mfint.39.12.1655.

7. Yuzevych, V., Klyuvak, O., \& Skrynkovskyy, R. (2016). Diagnostics of the system of interaction between the government and business in terms of public e-procurement. Economic Annals-XXI, 160(7-8), 39-44. doi: https://doi.org/10.21003/ea.v160-08.

8. Dzhala, R. M., Savula, S. F., \& Yuzevych, V. M. (2014). Mathematical Model for Evaluation of Resource of Pipeline with corrosive Crack at loading intrinsic Pressure. Methods and Devices of Quality Control, 2(33), 123-126.

9. Din, M. M., Ithnin, N., Zain, A. M., Noor, N. M., Siraj, M. M., \& Rasol, R. M. (2015). An artificial neural network modeling for pipeline corrosion growth prediction. ARPN Journal of Engineering and Applied Sciences, 10(2), 512-519.

10. Liao, K., Yao, Q., Wu, X., \& Jia, W. A (2012). Numerical Corrosion Rate Prediction Method for Direct Assessment of Wet Gas Gathering Pipelines Internal Corrosion. Energies, 5(10), 3892-3907. doi: https://doi.org/10.3390/en5103892.

11. Cosham, A., \& Hopkins, P. (2004). The assessment of corrosion in pipelines - guidance in the pipeline. Pipeline Pigging and Integrity Management Conference (17-18th May 2004 - Amsterdam, The Netherlands), 1-31.

12. Zhang, H., Zhang, H., Zhao, X., Wang, Y., \& Li, N. (2016). Study of Thickness Effect on Fracture Toughness of High Grade Pipeline Steel. MATEC Web of Conferences, 67(Article Number 03016), 1-8. doi: https://doi.org/10.1051/matecconf/20166703016.

13. Skrynkovskyi, R. (2008). Investment attractiveness evaluation technique for machine-building enterprises. Actual Problems of Economics, 7(85), $228-240$.

14. Skrynkovskyi, R. M. (2011). Methodical approaches to economic estimation of investment attractiveness of machine-building enterprises for portfolio investors. Actual Problems of Economics, 118(4), 177-186.

15. Podgórski, J. (2017). The criterion for determining the direction of crack propagation in a random pattern composites. Meccanica, 52(8), 1923-1934. doi: https://doi.org/10.1007/s11012-016-0523-y.
16. Koman, B. P., \& Yuzevich, V. M. (2015). Energy Parameters of Interfacial Layers in Composite Systems: Graphene - ( $\mathrm{Si}, \mathrm{Cu}, \mathrm{Fe}, \mathrm{Co}, \mathrm{Au}, \mathrm{Ag}, \mathrm{Al}$, $\mathrm{Ru}, \mathrm{Hf}, \mathrm{Pb}$ ) and Semiconductor ( $\mathrm{Si}, \mathrm{Ge})-(\mathrm{Fe}, \mathrm{Co}, \mathrm{Cu}, \mathrm{Al}, \mathrm{Au}, \mathrm{Cr}, \mathrm{W}, \mathrm{Pb}$ ).

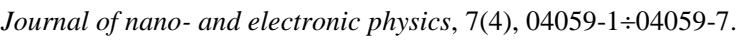

17. Kaneko, K., \& Narahashi, K. (2009). Study on Adhesive Strength Criterion under Complex Stresses. Journal of Solid Mechanics and Materials Engineering, 3(1), 49-63. doi: https://doi.org/10.1299/jmmp.3.49.

18. Monda, J., Marandi, M., Kozlova, J., Merisalu, M., Niilisk, A., \& Sammelselg, V. (2014). Protection and Functionalizing of Stainless Steel Surface by Graphene Oxide-Polypyrrole Composite Coating. J. Chem. Chem. Eng., 8, 786-793.

19. Salnikov, A. V., Sharygin, A. M., \& Ignatik, A. A. (2016). Strength and durability evaluation of pipes with defects for effective repair planning on the linear part of the main pipelines. Territorija "NEFTEGAS" [Oil and Gas Territory], 9, 114-121 (In Russ.). URL: https://tng.elpub.ru/jour/article/view/375.

20. Dzhala, R. M., Kaplun, A. V., Valiashek, V. B., \& Yuzevych, V. M. (2014). Model of the boundary of metals and the method of a small parameter in the problems of the theory of adhesion. Selection and information processing, 41(117), 20-27.

21. Wright, M., Guillen, P., Soltis, J. (2017). Risk management of stress corrosion cracking of buried pipelines. Rio Pipeline Conference \& Exhibition 2017, 1-7.

22. Colorado-Garrido, D., Ortega-Toledo, D. M., Hernández, J. A., González-Rodríguez, J. G., \& Uruchurtu, J. (2008). Neural networks for Nyquist plots prediction during corrosion inhibition of a pipeline steel. Journal of Solid State Electrochemistry, 13(11), 1715-1722. doi: https://doi.org/10.1007/s10008-008-0728-7.

23. Zhu, P., Yang, L., Li, Z., \& Sun, J. (2010). The shielding effects of the crack-tip plastic zone. International Journal of Fracture, 161(2), 131-139. doi: http://dx.doi.org/10.1007/s10704-011-9618-6.

24. Elishakoff, I. Interrelation Between Safety Factors and Reliability. NASA/CR-2001-211309; Florida Atl.Univ., Boca Raton, Florida. URL: https://ntrs.nasa.gov/archive/nasa/casi.ntrs.nasa.gov/20020011027.pdf.

25. El May, M., Saintier, N., Palin-Luc, T., Devos, O., \& Brucelle, O. (2018) Modelling of corrosion fatigue crack initiation on martensitic stainless steel in high cycle fatigue regime. Corrosion science, 133, 397-405. doi http://dx.doi.org/10.1016/j.corsci.2018.01.034.

26. Babych, M., Korobka, S., Skrynkovskyy, R., Korobka, S., \& Krygul, R. (2016). Substantiation of economic efficiency of using a solar dryer under conditions of personal peasant farms. Eastern-European Journal of Enterprise Technologies, 6(8(84)), 41-47. doi: http://dx.doi.org/10.15587/1729-4061.2016.83756.

27. Popova, N., Kataiev, A., Skrynkovskyy, R., \& Nevertii, A. (2019) Development of trust marketing in the digital society. Economic Annals-XXI, 176(3-4), 13-25. doi: https://doi.org/10.21003/ea.V176-02.

28. Koman, B., Skrynkovskyy, R., \& Yuzevych, V. (2018). Information Parameters of Synergetic Processes in Structures with Interfractional Boundaries. 2018 IEEE 8th International Conference Nanomaterials. Application \& Properties (NAP). doi: https://doi.org/10.1109/nap.2018.8914983.

29. Dzhala, R., Yuzevych, V., Lozovan, V., Mytsyk, A., Skrynkovskyy, R., \& Yasinskyi, M. (2019). Qualimetric analysis of pipelines with surface corrosion defects. Fracture Mechanics of Materials and Structural Integrity: Book of abstracts of the 6th International Conference (June 3-6, 2019, Lviv, Ukraine). Lviv: Karpenko Physico-Mechanical Institute of NASU, 125-126.

30. Klyuvak, A., Kliuva O., \& Skrynkovskyy, R. (2018). Partial Motion Blur Removal. 2018 IEEE Second International Conference on Data Stream Mining \& Processing (DSMP). doi: https://doi.org/10.1109/DSMP.2018.8478595.

31. Yuzevych, L., Skrynkovskyy, R., Yuzevych, V., Lozovan, V., Pawlowski, G., Yasinskyi, M., \& Ogirko, I. (2019). Improving the diagnostics of underground pipelines at oil-and-gas enterprises based on determining hydrogen exponent $(\mathrm{PH})$ of the soil media applying neural networks. Eastern-European Journal of Enterprise Technologies, 4(5(100)), 56-64. doi: http://dx.doi.org/10.15587/1729-4061.2019.174488 
32. Yuzevych, L., Yankovska, L., Sopilnyk, L., Yuzevych, V., Skrynkovskyy, R., Koman, B., Yasinska-Damri, L., Heorhiadi, N., Dzhala, R., \& Yasinskyi, M. (2019). Improvement of the toolset for diagnosing underground pipelines of oil and gas enterprises considering changes in internal working pressure. Eastern-European Journal of Enterprise Technologies, 6(5(102)), 23-29. doi: http://dx.doi.org/10.15587/1729-4061.2019.184247.

33. Dzhala, R. M., \& Yuzevych, L. V. (2019). Modeling of Relationships Between the Mechanoelectrochemical Parameters of the Metal Surface. Materials Science, 54, 753-759. doi https://doi.org/10.1007/s11003-019-00243-w.

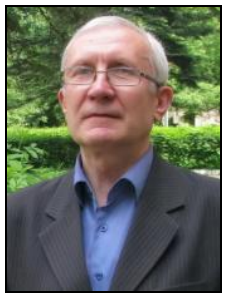

Volodymyr Yuzevych, DSc., Prof., Department of Electrophysical Methods of Non-Destructive Testing, Karpenko Physico-mechanical Institute of the NAS of Ukraine, Lviv, Ukraine;Area of scientific interests: Industrial and Technology Systems, Engineering Technological Systems, Fracture Mechanics of Materials and Structural Integrity; ORCID: http://orcid.org/0000-0001-5244-1850

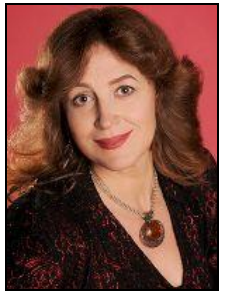

Nataliia Pavlenchyk, DSc., Prof.,

Head of the Department of Economics and Management, Lviv State University of Physical Culture, Lviv, Ukraine;Area of scientific interests: Engineering Technological Systems, Information and Control Systems, Industrial Economics, Problems of Economics and Management;ORCID:

http://orcid.org/0000-0001-6164-5644

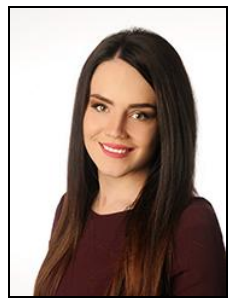

Olha Zaiats, PhD, Assoc. Prof.,

Department of Civil Law Disciplines, Lviv State University of Internal Affairs, Lviv, Ukraine;

Area of scientific interests: Industry Control Systems, Law and Innovation Activities, Intellectual Property;

ORCID: http://orcid.org/0000-0003-2872-5567

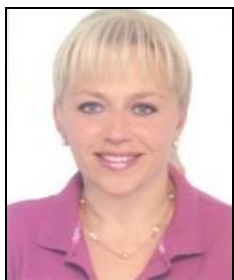

Nelli Heorhiadi, DSc., Prof.,

Department of Management and International Business, Lviv Polytechnic National University, Lviv, Ukraine;Area of scientific interests: Industry Control Systems, Engineering Technological Systems Innovative Processes, Industrial Economics;

ORCID: http://orcid.org/0000-0002-8348-5458

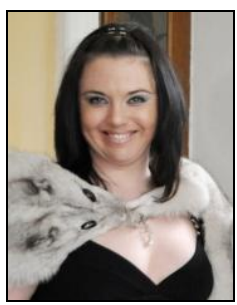

\section{Viktoriia Lakiza, PhD, Assoc. Prof.,}

Department of Management and International Business, Lviv Polytechnic National University, Lviv, Ukraine;Area of scientific interests: Information and Control Systems, Industry Control Systems, Problems of Economics and Management;

ORCID: http://orcid.org/0000-0002-6764-8536 